\section{Ultraviolet-B Radiation Damage on Kentucky Bluegrass. I. Antioxidant and Colorant Effects}

\author{
Erik H. Ervin, ${ }^{1}$ Xunzhong Zhang, ${ }^{2}$ and John H. Fike ${ }^{1}$ \\ Department of Crop and Soil Environmental Sciences, Virginia Polytechnic \\ Institute and State University, Blacksburg, VA 24061-0404
}

Additional index words. alpha-tocopherol, antioxidant enzyme activity, ascorbic acid, ascorbate peroxidase, catalase, chlorophyll fluorescence, photochemical efficiency, superoxide dismutase, turf injury

\begin{abstract}
High ultraviolet-B (UV-B; 290-320nm wavelength) may significantly contribute to kentucky bluegrass (Poa pratensis L.) sod death at harvest and transplanting. As terrestrial UV-B levels continue to increase due to a depletion of the stratospheric ozone layer this problem may worsen. Epidermal attenuation from pigments and detoxification of reactive oxygen species by antioxidant metabolites and enzymes are involved in plant defense against oxidative stress caused by UV-B. Our objective was to determine whether the attenuation and detoxification systems of kentucky bluegrass could be artificially boosted by exogenous applications of ascorbic acid (AA), alpha-tocopherol (AT), or a colorant before exposure to high levels of UV-B. Ascorbic acid, AT, and the colorant Green Lawnger (GL), were applied to plugs of mature kentucky bluegrass alone or in combination, and then subjected to artificial, continuous UV-B exposure $\left(70 \mu \mathrm{mol} \cdot \mathrm{m}^{-2} \cdot \mathrm{s}^{-1}\right)$; three greenhouse experiments were conducted. By 3 to 5 days after UV-B initiation, visual quality and photochemical efficiency, as measured by chlorophyll fluorescence were significantly reduced. However, in Expt. 1, AA alleviated decline of visual quality, delayed loss of photochemical efficiency, and increased recovery relative to the control. In Expt. 3, decreased endogenous AT and antioxidant enzyme activities were measured due to UV-B stress. Application of AA, AA + AT, or GL partially alleviated photochemical efficiency decline from 4 to 12 days after initiation of UV-B. In addition, application of the chemical treatments increased leaf tissue AT concentrations by $32 \%$ to $42 \%$, increased SOD activity by $30 \%$ to $33 \%$ and increased catalase activity by $37 \%$ to $59 \%$, relative to the control as measured 10 days after UV-B initiation. Greater AT concentration and SOD and catalase activities were associated with greater visual quality under UV-B stress. The results of these studies indicate that kentucky bluegrass UV-B tolerance may be increased by supplementing its pigment and antioxidant defense systems with foliar applications of AA, AT or GL.
\end{abstract}

A major advantage for landscape contractors is that sod provides an immediate cover at almost any time of the year. However, harvesting, hauling, and establishing kentucky bluegrass during periods of high heat and light intensity often presents the sod producer and landscaper with a 24- to 72-h window of opportunity for success. Supraoptimal temperature stress during sod transport can cause direct high temperature kill of turfgrass leaf tissues and negatively impact the physiological integrity of stem and root tissues (Heckman et al., 2001; King et al., 1982; Zhang et al., 2003). During this process, oxygen radicals develop that cause irreversible damage to essential cellular components such as lipids, proteins, and

Received for publication 14 Apr. 2003. Accepted for publication 31 Dec. 2003. This research was conducted as part of USDA-CSREES project no. VA-135660. Mention of a trademark, proprietary product, or vendor does not constitute a guarantee or warranty of the product by Virginia Tech or the U.S. Dept. of Agriculture and does not imply its approval to the exclusion of other products or vendors that also may be suitable.

${ }^{1}$ Assistant professor.

${ }^{2}$ Research scientist.
DNA (Polle, 1997). At harvest and replanting, exposure to high levels of short wavelength ultraviolet (UV, $<400 \mathrm{~nm}$ ) radiation increases oxidative stress, further decreasing the potential for posttransplant survival of heat-damaged sod. Greater transplant stress in the future is likely as terrestrial UV-B (280 to $320 \mathrm{~nm}$ ) levels increase due to a decrease in the stratospheric ozone layer caused by continued use of chemicals such as chlorofluorocarbons and methyl bromide (Mackerness, 2000).

Pigments, enzymes and antioxidants such as carotenoids, ascorbate, and alpha-tocopherol are constitutively present in leaves for protection against such stress. In the vast majority of plants, epidermal attenuation, not surface reflectance appears to be the dominant UV-B screening mechanism (Caldwell et al., 1983; Gausman et al., 1975). Epidermal attenuation is associated with pigments such as flavonoids and related phenolic compounds which strongly absorb UV light and transmit nondamaging longer wavelengths. However, as opposed to conifers, most herbaceous species appear particularly ineffective at epidermal attenuation of UV-B (Day et al., 1992). Induction of defense response mechanisms, including increased expression and activity of antioxidant enzymes such as ascorbate peroxidase and SOD, may limit the damage to herbaceous plants that is caused by high levels of UV exposure (Mackerness, 2000).

Endogenous levels of these antioxidants are not static; rather they fluctuate depending on developmental stage and changing environmental conditions such as light, temperature, and moisture availability (Polle, 1997). In general, plants grown under high light intensities contain higher antioxidant concentrations than plants grown under lower light intensities (Gillham and Dodge, 1987). There is no evidence that antioxidative systems can adjust instantaneously to changes in radiation (Foyer et al., 1989), but this is exactly the situation that sod stacked on pallets during transport is challenged with at transplantation: the need to quickly adjust from a low light to a high light field environment.

Exogenous applications of pigments or antioxidants may help sod recover more rapidly from the stresses of harvest, transport, and exposure to UV after a period of reduced light intensity. Application of a green turf colorant to creeping bentgrass (Agrostis stolonifera L.) before harvest increased tolerance to supraoptimal dark heat treatment followed by prolonged exposure to UV radiation (Schmidt and Zhang, 2001). Soaking of lettuce (Lactuca sativa L.) and spinach (Spinacia oleracea L.) roots in a $1500 \mathrm{mg} \cdot \mathrm{L}^{-1} \mathrm{~L}$-ascorbic acid before harvest resulted in marked increases in leaf ascorbic acid content (Inoue et al., 1998). Higher leaf ascorbic acid contents were maintained for at least three $\mathrm{d}$ of storage at $25^{\circ} \mathrm{C}$, implying significant gains in shelf life and nutritive value. These data suggest that application of colorants or antioxidants before kentucky bluegrass sod harvest may serve protective functions during storage at high temperatures and subsequent transplantation into a high UV-radiative field environment.

Before testing these assumptions in the field, the greenhouse experiments reported herein were designed to determine whether exogenous applications of a colorant, two antioxidants (ascorbic acid and alpha tocopherol), and a number of their combinations, might reduce the damaging effects of high UV-B radiation. More specifically, our objectives were to determine if these treatments might increase attenuation of UV-B irradiative damage or supplement the plant's antioxidative defense system, resulting in sustained photosystem II function, and less visual tissue damage.

\section{Materials and Methods}

Experiment 1. Mature 'Georgetown' kentucky bluegrass (Poa pratensis L.) grown on a Groseclose silt loam soil (a clayey, Kaolinitic, mesic Typic Hapludult, pH 6.0, OM 2.2\%) at the Virginia Tech Turfgrass Research Center, Blacksburg, Virginia, was used for this study. Nitrogen was applied at $49 \mathrm{~kg} \cdot \mathrm{ha}^{-1}$ with a $10 \mathrm{~N}-4.4 \mathrm{P}-8.3 \mathrm{~K}$ fertilizer in September 2000, and May and October 2001. The turfgrass was mowed weekly at a $6.3 \mathrm{~cm}$ height. Irrigation was applied to prevent moisture stress.

Kentucky bluegrass plugs $(10 \mathrm{~cm}$ diameter $\times 6 \mathrm{~cm}$ deep) were taken from field plots, put 
in PVC rings, and placed under a mist system in the greenhouse. Nitrogen was applied at 45 $\mathrm{kg} \cdot \mathrm{ha}^{-1}$ with a $20 \mathrm{~N}-8.7 \mathrm{P}-16.6 \mathrm{~K}$ fertilizer two $\mathrm{d}$ after the plugs were transplanted. The plugs were grown for 2 weeks before treatment.

The treatments were ascorbic acid, alphatocopherol, and a turf colorant, Green Lawnger (GL). Alpha-tocopherol (AT; 97\% purity) and ascorbic acid (AA; 97\% purity) were purchased from Sigma Chemical (St. Louis, Mo.). Green Lawnger was supplied by Becker Underwood, Inc. (Ames, Iowa). The chemical ingredients of GL are proprietary, however it can be generally characterized as a water-soluble phthalocyanine green pigment dispersed in resin (Herbst and Hunger, 1993). While AA is also water soluble, AT is lipophilic and required the addition of a surfactant (Aqua-Gro, Aquatrols Corporation, Cherry Hill, N.J.) at $0.05 \%$ to allow an evenly dispersed solution. Specific rates applied were 1) AT at $\left.50 \mathrm{mg} \cdot \mathrm{m}^{-2}, 2\right) \mathrm{AA}$ at $150 \mathrm{mg} \cdot \mathrm{m}^{-2}$, 3) $\mathrm{GL}$ at $5.25 \mathrm{~mL} \cdot \mathrm{m}^{-2}$, and 4) control. Light absorbance of each treatment solution was measured across the UV spectral range (250 to $400 \mathrm{~nm}$ ) and are presented as percent absorbance at each wavelength (Fig. 1). Treatment solutions containing colorant (GL or GL + AA) absorbed all light across the UV spectrum. The AA treatment solution absorbed limited amounts of UV light, and the combination of AA + AT had the same absorption pattern as that of AA because the AT solution had negligible UV-absorbing capacity. Absorption of UV light by AA or $\mathrm{AA}+\mathrm{AT}$ decreased from $\approx 68 \%$ at $250 \mathrm{~nm}$ to $<1 \%$ at $310 \mathrm{~nm}$. The treatments were sprayed onto kentucky bluegrass foliage using $60 \mathrm{~mL}$ syringes with needles on March 15, 2001. The treated turfgrass was not irrigated for $24 \mathrm{~h}$.

Twenty-four hours after treatment, the plugs were placed under artificial UV-B (70 $\mu \mathrm{mol} \cdot \mathrm{m}^{-2} \cdot \mathrm{s}^{-1}$ ) provided by three $40 \mathrm{~W} \mathrm{UV}-\mathrm{B}$ fluorescent lamps (Phillips UVB-313, Q-Panel Lab Products, Cleveland, Ohio). The UV-B was measured using an ultraviolet meter (which measures total UV irradiation between 250 and $400 \mathrm{~nm}$ ) from Apogee Instruments, Inc. (Logan, Utah). The meter was placed vertically with the sensor $0.5 \mathrm{~m}$ below the UV-B source.

The plugs were spaced evenly $(2.5 \mathrm{~cm})$, kept $0.5 \mathrm{~m}$ below the UV-B source, and grown under continuous UV-B in a greenhouse maintained at $22 \pm 2{ }^{\circ} \mathrm{C}$. Daylength averaged $11 \mathrm{~h}$. Plugs were subjected to UV-B from 16 to 26 Mar. and irrigated three times a week to prevent moisture stress. On 27 Mar., the plugs were removed from UV-B treatment and placed under a mist system for recovery.

The function of the photosynthetic system was measured indirectly by determining chlorophyll fluorescence using a dual wavelength fluorometer (OS-50, Opti-sciences, Inc., Tyngsboro, Massachusetts). Photochemical efficiency (Fv690nm/Fm690nm; that is, a ratio of variable fluorescence to maximum fluorescence at $690 \mathrm{~nm}$ ) was determined from chlorophyll fluorescence signals (Zhang and Schmidt, 2000). Visual turf quality during stress and recovery periods was rated based on a scale of 1 to 9 , with 9 indicating the best quality.
Experiment 2. Kentucky bluegrass plugs $(15 \mathrm{~cm}$ diameter $\times 6 \mathrm{~cm}$ deep) were taken from the same field plots as described in Expt. 1. The treatments included 1) AA, 2)AT, 3) $\mathrm{AA}+\mathrm{AT}, 4) \mathrm{GL}$, and 5) control. The rates and application methods remained the same as in Expt. 1. The plugs were treated on 31 May and placed under continuous UV irradiation from 1 through 12 June 2001. On 13 June, UV-B treatment ceased and the plugs were allowed to recover under a mist system. Photochemical efficiency and turf quality were determined as described for Expt. 1.

Experiment 3. Kentucky bluegrass plugs $(15 \mathrm{~cm}$ diameter $\times 6 \mathrm{~cm}$ deep) were taken from the same field plots as described in Expt. 1. The treatments included 1) AA, 2) AT, 3) $\mathrm{AA}+\mathrm{AT}$, 4) GL, 5) AA + GL, and 6) control. The rates and application method of the treatments remained the same as those in Expt. 1. The plugs were treated on 24 Jan. 2002 and placed under continuous UV-B from 25 Jan. through 4 Feb. 2002. On 5 Feb., UV-B stress was discontinued and the plugs were placed under a mist system and allowed to recover. Photochemical efficiency and visual turf quality were determined as described for Expt. 1. Leaf samples for antioxidant concentration and activity were taken from each experimental unit at 1,5 , and $10 \mathrm{~d}$ after UV-B initiation. The samples were immediately frozen with liquid $\mathrm{N}_{2}$ and stored at $-80{ }^{\circ} \mathrm{C}$ until laboratory analyses could be performed.

Alpha-tocopherol analysis. Alpha-tocopherol analysis was based on the methods of Tanaka et al., 1990 and Zhang and Schmidt, 1997. Frozen leaf segments $(500 \mathrm{mg}$ ) were crushed in liquid nitrogen and ground with a pestle in an ice-cold mortar containing 10 $\mathrm{ml}$ of $80 \%$ ethanol with $0.01 \%$ butylated hydroxytoluene (BHT). The homogenates were centrifuged at $4{ }^{\circ} \mathrm{C}$ for $20 \mathrm{~min}$ at 12000 $g_{\mathrm{n}}$. Using $6 \mathrm{~mL}$ of the clear supernatant, 1.0 $\mathrm{mL}$ of $\mathrm{n}$-hexane $(85 \%)$ was added and the mixture was fully agitated with a Vortex Mixer (Scientific Industries, Inc., Bohermia, N.Y.) for $2 \mathrm{~min}$. Two hours after agitation of the mixture, the upper layer of n-hexane in the mixture was collected and filtered with a Nylon Acrodisc $13-\mathrm{mm} \times 0.2-\mu \mathrm{m}$ filter and stored in sample vial flushed with $\mathrm{N}_{2}$ gas. The highperformance liquid chromatography (HPLC) system consisted of an HPLC pump (HP 1100, Hewlett Parkard Company, Palo Alto, Calif.), an automatic sampler, a programmable fluorescence detector (HP 1046 A, Hewlett Parkard Co., Palo Alto, Calif.), and an HPLC system controller (Chemstation Plus Family, Rev. A.08.01, Agilent Technolgies, Inc., Palo Alto, Calif.). Separations were performed on an analytical column of Supelcosil LC-Si (4.6 $\times 250 \mathrm{~mm}$ ) from Supelco Company (Bellefonte, $\mathrm{Pa}$.$) and filtered with a guard column (50 \times 4.6$ $\mathrm{mm})$ at room temperature. The mobile phase was a mixture of 99 hexane : 1 isopropanol. Alpha-tocopherol was detected by measuring the fluorescence intensity at $325 \mathrm{~nm}$ while exciting at $292 \mathrm{~nm}$. An AT standard from Sigma Chemical (St. Louis, Mo.) was used to develop a standard curve for the calculation of AT concentration in the samples.

Antioxidant enzyme analyses. Frozen leaf samples $(0.25 \mathrm{~g})$ were crushed with liquid nitrogen and extracted with a pestle in an ice-cold mortar with $4 \mathrm{~mL}$ of $0.05 \mathrm{M} \mathrm{Na}_{2} \mathrm{HPO}_{4} /$ $\mathrm{NaH}_{2} \mathrm{PO}_{4}(\mathrm{pH} 7.0)$ buffer containing $0.2 \mathrm{~mm}$ ethylenediamine-tetracetic acid (EDTA), and $1 \%$ polyvinyl-pyrrolidone (PVP). The homogenates were centrifuged at $4{ }^{\circ} \mathrm{C}$ for $20 \mathrm{~min}$ at $13000 g_{\mathrm{n}}$. The supernatants were collected and used for assays of enzymatic activities.

Superoxide dismutase activity. Superoxide dismutase activity was determined according to the method of Giannopolitis and Ries (1977). The 3-mL reaction mixture contained $63 \mu \mathrm{M}$ nitroblue tetrazolium (NBT), $1.3 \mu \mathrm{M}$ riboflavin, $13 \mathrm{~mm}$ methionine, $0.1 \mathrm{~mm}$ EDTA, $50 \mathrm{~mm}$ potassium phosphate buffer ( $\mathrm{pH} 7.8$ ), and $30 \mu \mathrm{L}$

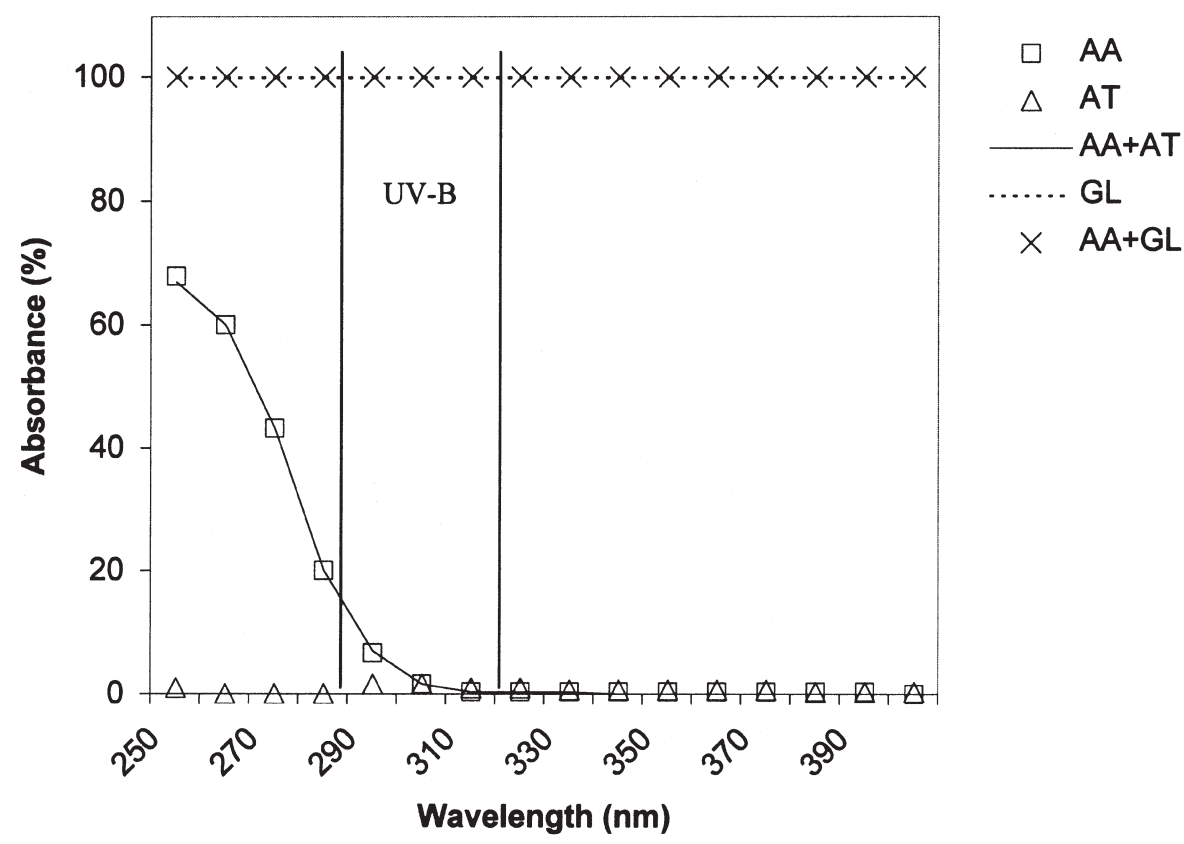

Fig. 1.Ultraviolet absorbance of treatment solutions (the solutions were diluted 100 times before measurement using a Thermo Spectronic spectrophotometer). 
enzyme extract. The riboflavin was added last. Test tubes containing the mixture were placed under one circular fluorescent lamp (irradiance $\left.=60 \mu \mathrm{mol} \cdot \mathrm{m}^{-2} \cdot \mathrm{s}^{-1}\right)$ at room temperature $\left(25^{\circ} \mathrm{C}\right)$. The reaction was initiated by switching on the light and slowly rotating sample tubes under the light for $10 \mathrm{~min}$.

Absorbance at $560 \mathrm{~nm}$ was measured with a Biomate 3 spectrophotometer (Thermo Spectronic, Rochester, N.Y.). A nonirradiated mixture without enzyme extract served as a blank and an irradiated mixture without enzyme extract served as a control. One unit of SOD activity was defined as the amount of enzyme required to cause $50 \%$ inhibition of the rate of NBT reduction.

Catalase activity. Catalase activity was determined by the method of Chance and Maehly (1955). The decomposition of $\mathrm{H}_{2} \mathrm{O}_{2}$ was measured by following the decline in absorbance at $240 \mathrm{~nm}$ for $2 \mathrm{~min}$. The $3 \mathrm{~mL}$ reaction mixture contained $50 \mathrm{~mm}$ phosphate buffer ( $\mathrm{pH} 7.0$ ), $15 \mathrm{~mm} \mathrm{H}_{2} \mathrm{O}_{2}$, and $0.1 \mathrm{~mL}$ enzyme extract. The reaction was started with the addition of the enzyme extract. Absorbance at $240 \mathrm{~nm}$ was read every $20 \mathrm{~s}$. One unit of catalase activity was defined as a change of 0.01 absorbance/min caused by the enzyme extract (Zhang and Kirkham, 1994).

Ascorbate peroxidase activity. Ascorbate peroxidase (APX) activity was determined by following the reduction in absorbance at 290 nm due to AA oxidation for $1 \mathrm{~min}$ (Nakano and Asada, 1981). The $3 \mathrm{~mL}$ reaction mixture contained 0.5 mmAA, $0.1 \mathrm{~mm} \mathrm{H}_{2} \mathrm{O}_{2}, 0.1 \mathrm{mmEDTA}$, $50 \mathrm{~mm}$ Na-phosphate buffer (pH 7.0), and 0.1 mL enzyme extract. The reaction was initiated by adding $\mathrm{H}_{2} \mathrm{O}_{2}$. One unit of APX activity was defined as a change of 0.1 absorbance $\cdot \mathrm{min}^{-1}$ caused by the enzyme extract.

Determination of protein concentration. Since the activities of antioxidant enzymes are presented on a protein basis, protein concentration for each sample was analyzed by the bicinchoninic (BCA) method (Sigma, Saint Louis, Mo.), with bovine serum albumin serving as the standard.

Statistical analyses. Treatments were arranged in randomized complete blocks with three replications. Data were analyzed using analysis of variance (ANOVA) and means separations were performed using a Fisher's protected LSD test at a 95\% probability level (SAS, 1988). In addition, Spearman correlation coefficients of antioxidants with visual quality and photochemical efficiency were determined for each treatment (SAS, 1988).

\section{Results}

Experiment 1. All kentucky bluegrass plants began the trial with equivalent photochemical efficiency and no differences in visual quality (Figs. 2 and 3). Three d after initiation of continuous UV-B, AA-treated bluegrass had greater photochemical efficiency when compared to the control; at five d, both AA and GL had higher photochemical efficiency, while only AA had better visual quality. From day 1 to day 10 of UV-B exposure, the photochemical efficiency of AA-treated plants fell $50 \%$

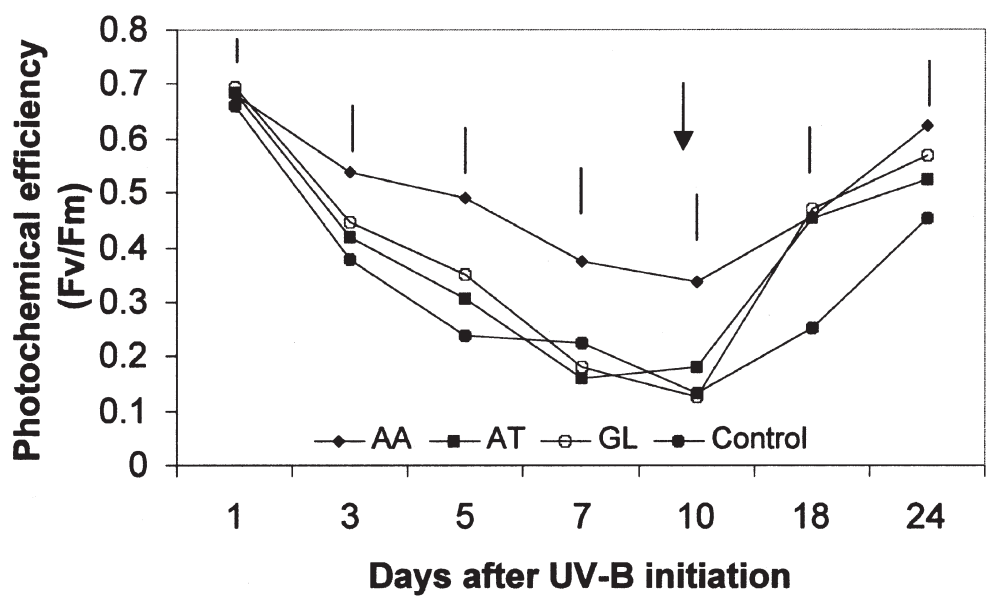

Fig. 2. Photochemical efficiency (Fv/Fm) of kentucky bluegrass as influenced by ascorbic acid (AA), alpha-tocopherol (AT), and GreenLawnger (GL) under UV irradiation stress. Plugs were treated on 15 Mar. and subjected to UV stress from 16 through 26 Mar. at which time they were removed from UV and allowed to recover under optimal greenhouse environmental conditions. Bars indicate 1 sd at $P=0.05$; the arrow indicates date of UV removal; Expt. 1.

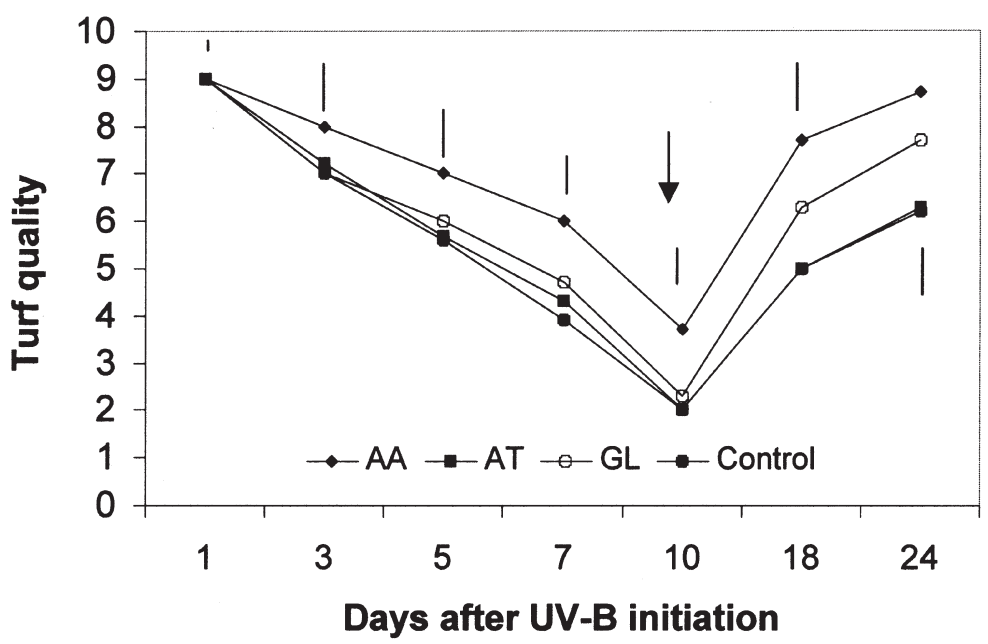

Fig. 3. Visual turf quality ( $1=$ completely dead tissue $)$ of kentucky bluegrass as influenced by ascorbic acid (AA), alpha-tocopherol (AT) and GreenLawnger (GL) under UV irradiation stress. Plugs were treated on 15 Mar. and subjected to UV stress from 16 through 26 Mar. at which time they were removed from UV and allowed to recover under optimal greenhouse environmental conditions. Bars indicate $1 \mathrm{sd}$ at $P=0.05$; the arrow indicates date of UV removal; Expt. 1.

vs. an $80 \%$ decline for control plants. Eight d after removal of UV-B, (day 18), bluegrass in all three treatments had better recovery of photochemical efficiency, but only plugs treated with AA and GL displayed greater visual quality relative to controls. By day 24 , the photochemical efficiency and visual quality levels of the AA-treated bluegrass had almost fully returned to $\mathrm{d} 1$ levels.

Experiment 2. In Expt. 2 our objectives were to verify the results of Expt. 1, while also investigating whether the protective properties of AA might be increased through combination with AT. At d 4 of UV-B irradiation exposure, $\mathrm{AA}, \mathrm{AT}$, and AA + AT treatments maintained greater photochemical efficiency (Fig. 4). By day 12 , only AA and AA + AT treatments had higher sustained photochemical efficiency. At day 12 and day 16 GL had greater visual quality relative to the control (Fig. 5; 0 and 4 $\mathrm{d}$ after removal from UV-B), but photochemical efficiency measurements did not indicate a significant GL treatment advantage. Perhaps the discrepancy between the visual and photochemical data is explained by the artificial greening imparted by the colorant. During recovery, the photochemical efficiency of all antioxidant-treated bluegrass recovered quicker than the control (day 16). Following an extended recovery period ( $42 \mathrm{~d}$ ), both AA- and GL-treated bluegrass had greater measured photochemical efficiency, and all treatments displayed greater visual quality relative to the control.

Experiment 3. Ultraviolet irradiation stress caused a 55\% reduction of photochemical efficiency during the 10-d treatment period. When measured at $10 \mathrm{~d}$ after UV-B, all treatments, except AA + GL, increased photochemical efficiency by $68 \%$ to $111 \%$ relative to the control. Eighteen d after removal of UV-B, photochemical efficiency was greater for all treatments except AA + GL (Fig. 6).

Ultraviolet irradiation caused severe 


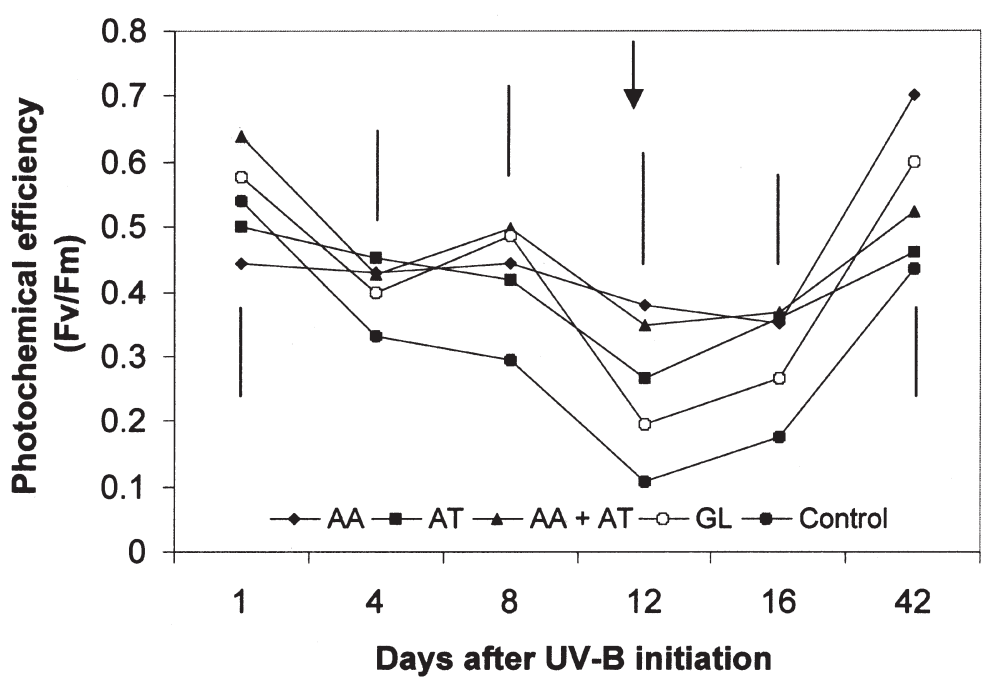

Fig. 4. Photochemical efficiency (Fv/Fm) of kentucky bluegrass as influenced by ascorbic acid (AA), alpha-tocopherol (AT), and GreenLawnger (GL) under UV irradiation stress. Plugs were treated on 31 May and subjected to UV irradiation stress from 1 through 12 June at which time they were removed from UV and allowed to recover under optimal greenhouse environmental conditions. Bars indicate $1 \mathrm{sd}$ at $P=0.05$; the arrow indicates date of UV removal; Expt. 2.

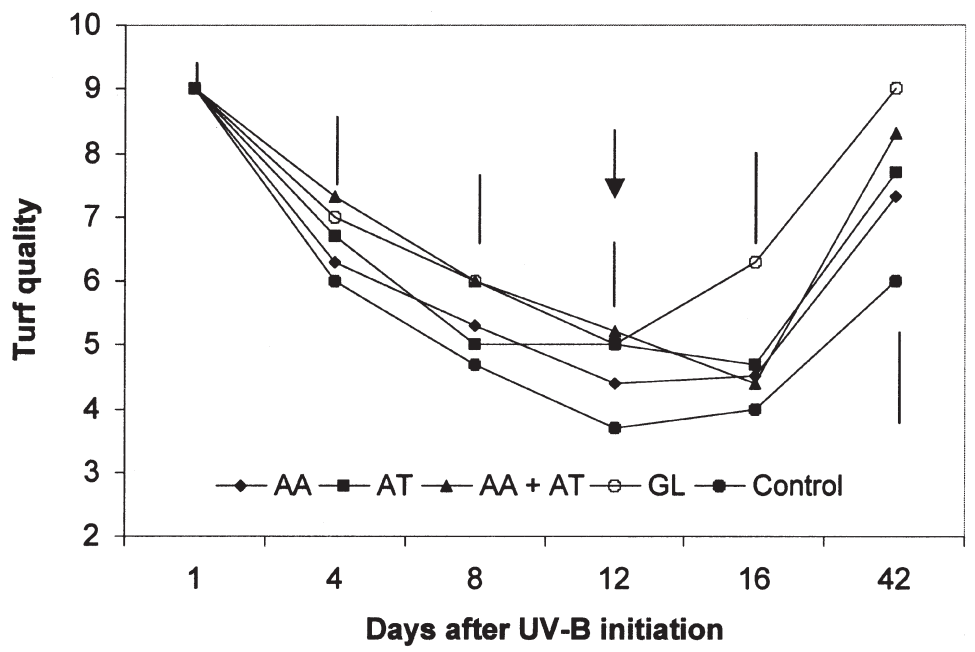

Fig. 5. Visual turf quality ( 1 = completely dead tissue) of kentucky bluegrass as influenced by ascorbic acid (AA), alpha-tocopherol (AT) and GreenLawnger (GL) under UV irradiation stress. Plugs were treated on 31 May and subjected to UV irradiation stress from 1 through 12 June at which time they were removed from UV and allowed to recover under optimal greenhouse environmental conditions. Bars indicate $1 \mathrm{sd}$ at $P$ $=0.05 ;$ the arrow indicates date of UV removal; Expt. 2 .

damage to the kentucky bluegrass (Fig. 7). All treatments increased visual quality when measured at $10 \mathrm{~d}$ after UV-B initiation. Losses in the visual quality of the control $\left(r=0.91^{* *}\right)$, $\mathrm{AA}+\mathrm{AT}\left(r=0.93^{* *}\right)$, and AA + GL $\left(r=0.84^{* *}\right)$ treatments were highly correlated with reductions in photochemical efficiency over the 10-d irradiation period. Following $18 \mathrm{~d}$ of recovery (day 28), all treatments had regained greater visual quality than the control.

One d after UV-B initiation, leafAT concentrations were equivalent across all treatments (Table 1). However, at $\mathrm{d} 5$ all treatments except AA + AT had greater endogenous AT levels relative to the control. By d 10, AT contents had been depleted by $38 \%$ to $63 \%$, but plants from all treatments had greater AT levels than those of the control. Higher sustained photochemical efficiency readings were correlated five d of UV-B (Table 1). However, relative to the control, bluegrass pre-treated with AT or AA + GL maintained $42 \%$ and $38 \%$ higher catalase activity, respectively, at five $\mathrm{d}$ after UV-B initiation. At the conclusion of UV-B treatment (d 10), four of the five chemical pre-treatments resulted in $37 \%$ to $59 \%$ greater maintenance of catalase activity. Accordingly, $\mathrm{GL}\left(r=0.69^{* *}\right), \mathrm{AA}+\mathrm{GL}\left(r=0.91^{* *}\right)$, and AA $+\mathrm{AT}\left(r=0.86^{* *}\right)$ were correlated with greater photochemical efficiency maintenance over the 10-d irradiation period. Ascorbate peroxidase activity was, in general, unaffected by chemical pre-treatments or UV irradiation over the 10-d study period (Table 1 ).

\section{Discussion}

The results of this study indicate that continuous UV-B $\left(70 \mu \mathrm{mol} \cdot \mathrm{m}^{-2} \cdot \mathrm{s}^{-1}\right)$ caused significant visual and photosynthetic damage to kentucky bluegrass in a short period of time $(<10 \mathrm{~d})$. This is consistent with the results of Noorudeen and Kulandaivelu (1982), Perez-Rodriguez et al. (1998), Strid and Porra (1992), and Schmidt and Zhang (2001). Brandle et al. (1977) noted that PSII activity is impaired in Pisum plants exposed to UV-B. Noorudeen and Kulandaivelu (1982) indicated that UV-B inactivated the PSII reaction center. Teramura and Ziska (1996) concluded that increased UV-B decreases activity of the PSII complex resulting in reduced electron transport, photosynthetic capacity, and chlorophyll content. In addition, UV-B may affect photosynthesis indirectly by photo-bleaching and photo-degradation of photosynthetic pigments (Strid et al., 1990; Teramura, 1996). The results of this study indicate that kentucky bluegrass is sensitive to UV irradiation damage of the photosynthetic apparatus, resulting in rapid and extensive leaf injury.

Our data indicate that UV-B resulted in depleted endogenous levels of AT and activities of the antioxidant enzymes SOD and catalase. However, ascorbate peroxidase activity was unaffected by UV-B treatment. This is consistent with the results of Costa et al. (2002) who reported that SOD activity decreased while ascorbate peroxidase activity remained unchanged in sunflower (Helianthus annuus L.) cotyledons subjected to UV-B stress for 50 and $100 \mathrm{~min}$. Alpha-tocopherol stabilizes chloroplast membranes and quenches singlet oxygen. Superoxide dismutase is the most efficient scavenger of the superoxide anion and an essential component of the ascorbateglutathione cycle for detoxification of ROS Catalase and ascorbate peroxidase react with $\mathrm{H}_{2} \mathrm{O}_{2}$ to form water and oxygen (Polle, 1997). Higher levels of these susbstances during UV exposure should be positively associated with greater tolerance to this stress.

The positive relationships between turf quality and antioxidant concentration and activity found in this study are consistent with the results of Zhang and Schmidt (1999) who showed an association between antioxidant activity and drought tolerance of kentucky bluegrass. Among the antioxidants examined herein, higher sustained levels of AT, SOD, and catalase were associated with greater turf 
quality under UV-B stress. Our results indicate that application of AA, AT, the turf colorant GL, and some of their combinations forestalled the decline of the endogenous AT pool and the activity of SOD and catalase in kentucky bluegrass under severe UV-B stress. Our results are supported by those of Schmidt and Zhang (2001) who reported that certain plant biochemical regulators and GL significantly reduced UV-B injury of kentucky bluegrass as determined by photochemical efficiency responses.

The impact of the antioxidant and GL treatments on kentucky bluegrass resistance to UV-B stress may involve two different mechanisms. Applications of colorants such as GL most likely increase epidermal attenuation by absorbing UV wavelengths and transmitting nondamaging longer wavelengths as suggested by spectrophotometric absorbance. The result may be a conserved pool of antioxidants for longer protection against oxidative damage. Exogenous AA and AT applications may enhance endogenous antioxidant concentrations, resulting in a greater ability to detoxify ROS and maintain photosynthetic activity. Supplementing the pool of leaf antioxidants may also reduce the rate at which antioxidant enzyme activity declines.

As levels of stratospheric ozone continue to decline, with concomitant increases in UV-B radiant flux, the damaging effects of UV-B on transplanted sod will likely become more severe. The results of these preliminary studies show that foliar supplementation of antioxidants such as AA or the application of UV-B attenuators such as GL may significantly reduce UV-B damage and allow for greater summer transplantation success of kentucky bluegrass sod. Field experiments to test the effectiveness of these treatments during summer sod harvest, storage, and transplantation remain to be conducted.

\section{Literature Cited}

Brandle, J.R. W.F. Campbell, W.B. Sisson, and M.M. Caldwell. 1977. Net photosynthesis, electron transport capacity and ultrastructure of Pisum sativum L. exposed to ultraviolet-B radiation. Plant Physiol. 60:165-169.

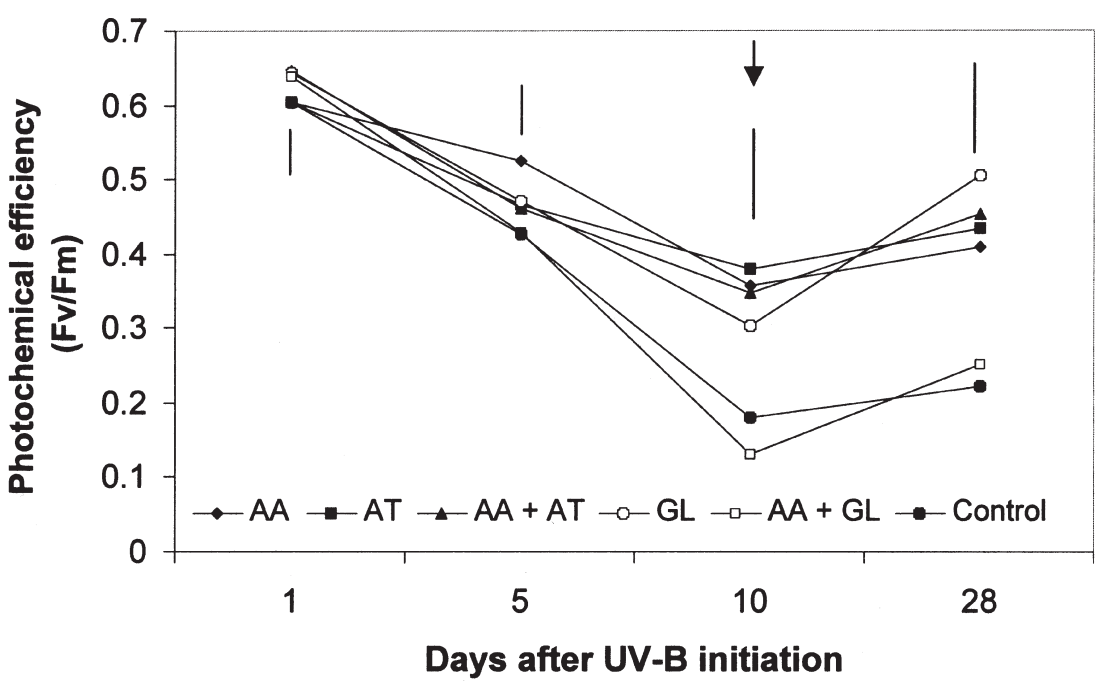

Fig. 6. Photochemical efficiency (Fv/Fm) of kentucky bluegrass as influenced by ascorbic acid (AA), alpha-tocopherol (AT), and GreenLawnger (GL) under UV irradiation stress. Plugs were treated on $25 \mathrm{Jan}$. and subjected to UV radiation stress from 26 Jan. through 4 Feb. at which time they were removed from UV and allowed to recover under optimal greenhouse environmental conditions. Bars indicate $1 \mathrm{sd}$ at $P=0.05$; the arrow indicates date of $\mathrm{UV}$ removal; Expt. 3.

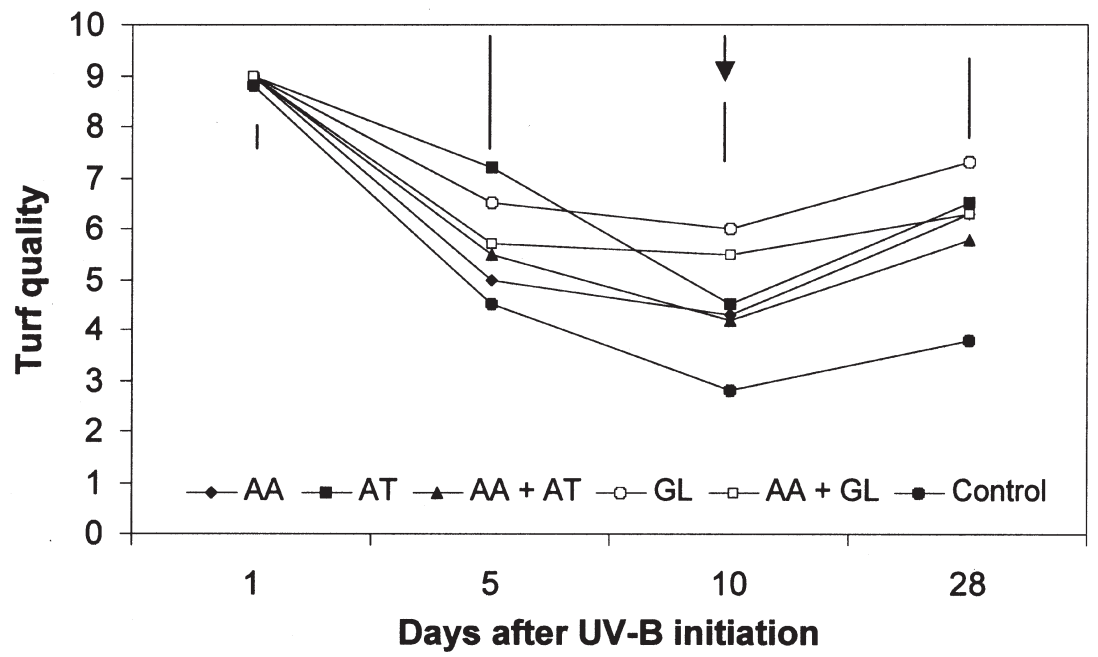

Fig. 7. Visual turf quality of kentucky bluegrass as influenced by ascorbic acid (AA), alpha-tocopherol (AT), and GreenLawnger (GL) under UV irradiation stress. Plugs were treated on 25 Jan. and subjected to UV radiation stress from 26 Jan. through 4 Feb., at which time they were removed from UV and allowed to recover under optimal greenhouse environmental conditions. Bars indicate 1sd at $P=0.05$; the arrow indicates date of UV removal; Expt. 3 .

Table 1. Alpha-tocopherol concentration and antioxidant enzyme activities of kentucky bluegrass as influenced by vitamin and colorant treatments under UV-B stress.

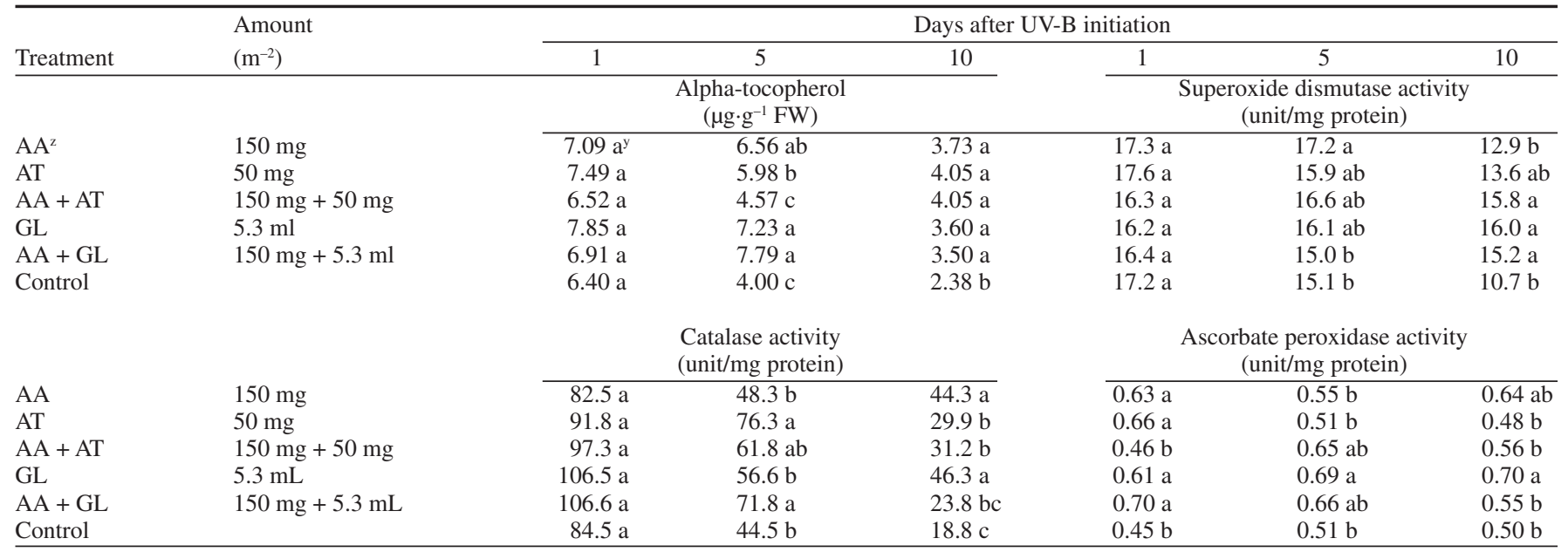

${ }^{\mathrm{z}} \mathrm{AA}=$ ascorbic acid; $\mathrm{AT}=$ alpha-tocopherol; GL = greenlawnger turf colorant.

${ }^{y}$ Values of each data set marked with same letter within same column are not different

significantly at $\operatorname{LSD}_{(0.05)}$. 
Caldwell, M.M., R. Robberecht, and S.D. Flint. 1983. Internal filters: prospects of UV-acclimation in higher plants. Phys. Planta. 58:445-450.

Chance, B. and A.C. Maehly. 1955. Assay of catalase and peroxidases. Methods Enzymol. 2:764-775.

Costa, H., M. Susana, S.M. Gallego, and M.L. Tomaro. 2002. Effect of UV-B radiation on antioxidant defense system in sunflower cotyledons. Plant Sci. 162:939-945.

Day, T.A., T.C. Vogelmann, and E.H. DeLucia. 1992. Are some plant life forms more effective than others in screening out ultraviolet-B radiation? Oecologia 92:513-519.

Gausman, H.W., R.P. Rodriguez, and D.E. Escobar. 1975. Ultraviolet radiation reflectance, transmittance, and absorbance by plant leaf epidermises. Agron. J. 83:391-396.

Giannopolitis, C.N. and S.K. Ries. 1977. Superoxide dismutase. I. Occurrence in higher plants. Plant Physiol. 59:309-314.

Gillham, D. and A. Dodge. 1987. Chloroplast superoxide and hydrogen peroxide scavenging systems from pea leaves: Seasonal variations. Plant Sci. 50:105-109.

Heckman, N.L., G.L. Horst, R.E. Gaussoin, and K.W. Frank. 2001. Storage and handling characteristics of trinexapac-ethyl treated kentucky bluegrass sod. HortScience 36:1127-1130.

Herbst, W. and K. Hunger. 1993. Industrial organic pigments. VCH, New York.

Inoue, K., N. Oyama, S. Kondo, Y. Hyata, and H. Yokota. 1998. Production of ascorbic acid enriched vegetables: Absorption of an L-ascorbic acid solution and the effect on foliar exogenous ascorbic acid content. J. Hort. Sci. Biotechnol.
73(5):681-686.

King J.W., J.B. Beard, and P.E. Rieke. 1982. Factors affecting survival of kentucky bluegrass sod under simulated shipping conditions. J. Amer. Soc. Hort. Sci. 107:634-637.

Mackerness, S.A.H. 2000. Plant responses to ultraviolet-B(UV-B: 280-320 nm) stress: What are the key regulators? Plant Growth Regulat. 32:27-39

Nakano, Y. and K. Asada. 1981. Hydrogen peroxide is scavenged by ascorbate-specific peroxidase in spinach chloroplasts. Plant Cell Physiol. 22:867-880.

Noorudeen, A.M. and G. Kulandaivelu. 1982. On the possible site of inhibition of photosynthetic electron transport by ultraviolet-B (UV-B) radiation. Physiol. Plant 55:161-166.

Perez-Rodriguez, E., I. Gomez, U. Karsten, and F.L. Figueroa. 1998. Effects of UV radiation on photosynthesis and excretion of UV-absorbing compounds of Dasycladus vermicularis (Dasycladales, chlorophyta) from southern Spain. Phycologia 37:379-387.

Polle, A. 1997. Defense against photooxidative damage in plants, p. 623-666. In: J.G. Scandalios (ed.). Oxidative stress and the molecular biology of antioxidant defenses. Cold Spring Harbor Lab Press, Plainview, N.Y.

SAS Institute Inc. 1988. SAS/STAT use's guide. release 6.03 ed. SAS Inst. Inc., Cary, N.C.

Schmidt, R.E. and X. Zhang. 2001. Alleviation of photochemical activity decline of turfgrasses exposed to soil moisture stress or UV radiation. Int. Turfgrass Res. J. 9: 340-346.

Strid, A. and R.J. Porra. 1992. Alterations in pigment content in leaves of Pisum sativum after exposure to supplementary UV-B. Plant Cell
Physiol. 33:1015-1023.

Strid A., W.S. Chow, and J. Anderson. 1990. Effects of supplementary ultraviolet-B radiation on photosynthesis in Pisum sativum. Biochem. Biophy Acta. 1020:260-268.

Tanaka, K., R. Masuda, T. Sugimato, K. Omasa, and T. Sakasi. 1990. Water deficiency-induced changes in the contents of defensive substances against active oxygen in spinach leaves. Agr. Biol. Chem. 54:2629-2634.

Teramura, A.H. 1996. Ultraviolet-B radiation and photosynthesis, p. 435-450. In: Neil R. Baker (ed.). Photosynthesis and the environment. Kluwer Academic Publ., Dordrecht, The Netherlands.

Zhang, J. and M.B. Kirkham. 1994. Drought-stressinduced changes in activities of superoxide dismutase, catalase, and peroxidase in wheat species. Plant Cell Physiol. 35:785-791.

Zhang, X. and R.E. Schmidt. 1997. The impact of growth regulators on the alpha-tocopherol status in water-stressed Poa pratensis. Intl. Turfgrass Res. J. 8:1364-1371.

Zhang, X. and R.E. Schmidt. 1999. Antioxidant responses to hormone-containing products in kentucky bluegrass subjected to drought. Crop Sci. 39:545-551.

Zhang, X. and R.E. Schmidt. 2000. Application of trinexapac-ethyl and propiconazole enhances superoxide dismutase and photochemical activity in creeping bentgrass. (Agrostis stoloniferous var. palustris). J. Amer. Soc. Hort. Sci. 125:47-51.

Zhang, X., E. Ervin, and R.E. Schmidt. 2003. Plant growth regulators can enhance the recovery of kentucky bluegrass sod from heat injury. Crop Sci. 43(3):952-956. 